\section{O modelo principialista e o diagrama do SUS - uma abordagem lógica da distribuição de recursos escassos em saúde}

Ilario, Enidio

Faculdade de Ciências Médicas - FCM/UNICAMP E-mail: enidioilario@uol.com.br

Sá, Flávio Cesar de

Faculdade de Ciências Médicas - FCM/UNICAMP

Aoki, Francisco Hideo

Faculdade de Ciências Médicas - FCM/UNICAMP

PALAVRAS CHAVES: Principialismo, Lógica Diagramática, SUS, Recursos Escassos em Saúde.

Modelos são abstrações que implicam certo grau de simplificação frente à complexidade dos fenômenos que se quer explicar. No campo da ética biomédica, se destaca o modelo principialista padrão de Beauchamp e Childress, baseado em uma matriz formada por quatro princípios: beneficência (PB), não maleficência (PNM), autonomia (PA) e justiça (PJ). O modelo principialista é heurístico, possibilitando que diante de conflitos entre os princípios prevaleça aquele mais adequado à situação concreta. Neste trabalho, dá-se feição diagramática ao modelo principialista, partindo do pressuposto de que as relações lógicas são subjacentes a todo pensamento, e os diagramas mostram tais relações em estruturas espaciais integradas. A topologia dos conceitos, ao desvelar relações lógicas presentes nas estruturas dos modelos, permite uma melhor compreensão de um campo integrado de princípios implicados no raciocínio moral. Ilustramos a aplicabilidade deste tipo de modelo através da sobreposição do diagrama do modelo principialista padrão com o diagrama do sistema de princípios subjacentes ao Sistema Único de Saúde (SUS) implantado no Brasil a partir da Constituição de 1988. O SUS estrutura-se sob os princípios da universalidade, da equidade e da integralidade, o que quer dizer, acesso irrestrito de todos os cidadãos, sem qualquer exclusão, além da proteção prioritária aos mais vulneráveis. Em países em desenvolvimento, os recursos em saúde são escassos e tal problema é agravado no Brasil, pela competição com modelos privados beneficiados por generosa renúncia fiscal. Nesses últimos, prevalecem leis de mercado, a maximização do lucro e a consequente exclusão de cobertura, mesmo naquela parcela da população supostamente coberta, que acaba muitas vezes recorrendo ao SUS em tratamentos mais complexos e onerosos. O diagrama síntese que decorre desse exercício de lógica diagramática explicita aquilo que denominamos "triângulo das virtudes sanitárias". Virtudes no sentido de capacidade de obtenção de equidade, integralidade e universalidade, capazes de produzir saúde a partir de políticas públicas. Explicita-se desta forma que os sistemas de saúde universais são os únicos capazes de harmonizar ações afins com os princípios bioéticos fundamentais.
Evidencia-se também que, ao contrário do que liberais fundamentalistas acreditam, o PA não se esgota na autonomia do indivíduo em relação às suas escolhas por tal e qual tipo de atenção à saúde, mas, sobretudo é a expressão do controle do sistema pelos usuários, ou seja, pelos membros da comunidade. Dessa forma, do Princípio da Autonomia deriva outra importante característica do SUS, o controle social nas três esferas de governo, através dos conselhos de saúde.

\section{REFERÊNCIAS}

[1] ILARIO, I, PEREIRA JR, PAIXÃO JR, Revista Bioética. 2018; 26 (2): 198-206

[2] Ministério da Saúde, Lei 8.080 de 19/09/1990, Conselho Nacional de Saúde, DF, Brasil. Disponível: http://conselho.saude.gov.br/legislacao/lei8080_190990.htm

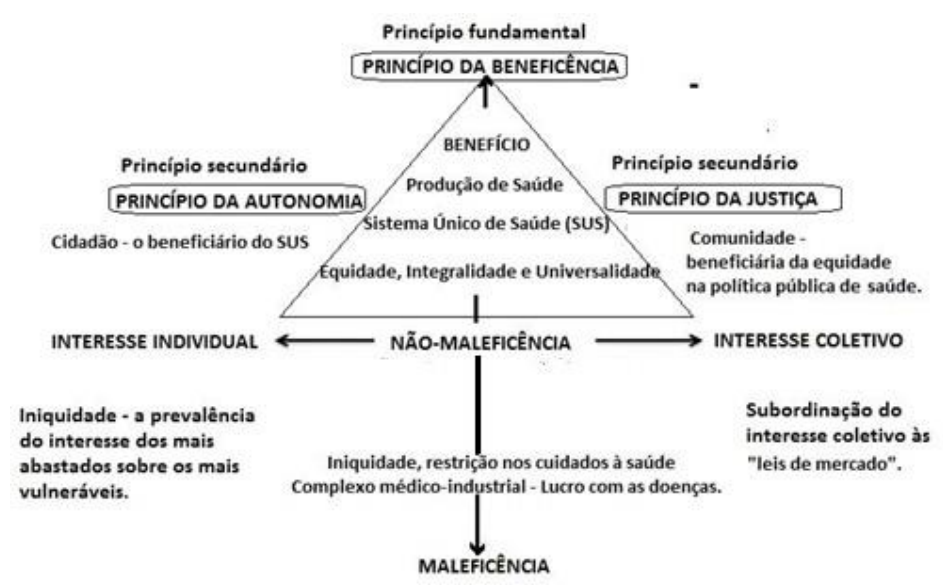

Diagrama: Principialismo, SUS e alocação de recursos escassos em saúde.

Ilario, Sá \& Aoki. O modelo principialista e o diagrama do SUS - uma abordagem lógica da distribuição de recursos escassos em saúde. Revista Brasiliera de Bioética. 2019. 